Audiology

Neurotology
Audiol Neurotol 2014;19:57-71

DOI: $10.1159 / 000355700$
Received: May 21, 2013

Accepted after revision: September 12, 2013

Published online: December 19, 2013

\title{
Availability of Binaural Cues for Bilateral Implant Recipients and Bimodal Listeners with and without Preserved Hearing in the Implanted Ear
}

\author{
René H. Gifford ${ }^{b} \quad$ Michael F. Dorman ${ }^{a} \quad$ Sterling W. Sheffield ${ }^{b}$ Kate Teece $^{c}$ \\ Amy P. Olund ${ }^{c}$ \\ ${ }^{a}$ Department of Speech and Hearing Science, Arizona State University, Tempe, Ariz., ${ }^{b}$ Department of Hearing and \\ Speech Sciences, Vanderbilt University, Vanderbilt Bill Wilkerson Center, Nashville, Tenn., and ' Department of \\ Otorhinolaryngology, Mayo Clinic, Rochester, Minn., USA
}

\section{Key Words}

Binaural cues · Bilateral cochlear implant · Bimodal hearing · Hearing preservation patients

\begin{abstract}
The purpose of this study was to examine the availability of binaural cues for adult, bilateral cochlear implant $(\mathrm{Cl})$ patients, bimodal patients and hearing preservation patients using a multiple-baseline, observational study design. Speech recognition was assessed using the Bamford-KowalBench Speech-in-Noise (BKB-SIN) test as well as the AzBio sentences [Spahr AJ, et al: Ear Hear 2012;33:112-117] presented in a multi-talker babble at a $+5 \mathrm{~dB}$ signal-to-noise ratio (SNR). Test conditions included speech at $0^{\circ}$ with noise presented at $0^{\circ}\left(\mathrm{S}_{0} \mathrm{~N}_{0}\right), 90^{\circ}\left(\mathrm{S}_{0} \mathrm{~N}_{90}\right)$ and $270^{\circ}\left(\mathrm{S}_{0} \mathrm{~N}_{270}\right)$. Estimates of summation, head shadow (HS), squelch and spatial release from masking (SRM) were calculated. Though nonwwe of the subject groups consistently showed access to binaural cues, the hearing preservation patients exhibited a significant correlation between summation and squelch whereas the bilateral and bimodal participants did not. That is to say, the two effects associated with binaural hearing summation and squelch - were positively correlated only for the listeners with bilateral acoustic hearing. This finding provides evidence for the supposition that implant recipients
\end{abstract}

with bilateral acoustic hearing have access to binaural cues, which should, in theory, provide greater benefit in noisy listening environments. It is likely, however, that the chosen test environment negatively affected the outcomes. Specifically, the spatially separated noise conditions directed noise toward the microphone (mic) port of the behind-the-ear (BTE) hearing aid and implant processor. Thus, it is possible that in more realistic listening environments for which the diffuse noise is not directed toward the processor/hearing aid mic, hearing preservation patients have binaural cues for improved speech understanding.

ㄷ) 2013 S. Karger AG, Basel

\section{Introduction}

There are a number of published studies documenting the respective benefits of bilateral cochlear implantation, bimodal hearing and hearing preservation cochlear implantation. Several studies have documented summation, head shadow (HS), binaural squelch (also commonly termed binaural unmasking) and spatial release from masking (SRM) for bilateral cochlear implant (CI) recipients [Schleich et al., 2004; Litovsky et al., 2006; Wackym et al., 2007; Buss et al., 2008; Zeitler et al., 2008; Eapen et al., 2009]. Since binaural hearing is not required for HS or

\section{KARGER}

(c) 2013 S. Karger AG, Basel

$1420-3030 / 13 / 0191-0057 \$ 38.00 / 0$

E-Mail karger@karger.com

www.karger.com/aud
René H. Gifford

Vanderbilt University, Department of Hearing and Speech Sciences

Vanderbilt Bill Wilkerson Center

Nashville, TN 37232 (USA)

E-Mail rene.h.gifford@Vanderbilt.edu 
SRM, the only effects that are solely indicative of binaural hearing are summation and squelch. In previous studies with bilateral-implant recipients, squelch estimates were quite small - in most cases ranging from 0.9 to $1.9 \mathrm{~dB}$ for adaptive or pseudoadaptive measures [Schleich et al., 2004; Litovsky et al., 2006] and 8-18 percentage points for fixed signal-to-noise ratio (SNR) measures [Laszig et al., 2004; Buss et al., 2008; Eapen et al., 2009; Verhaert et al., 2012].

In contrast to bilateral-implant users, bimodal listeners, without preserved hearing in the implanted ear, have exhibited greater variability and generally more modest estimates of the use of binaural cues. In a meta-analysis of 13 studies examining adult bimodal listeners, Schafer et al. [2007] reported significant bimodal summation (bimodal vs. CI alone) of 14 percentage points across studies for fixed SNR measures. For adaptive speech reception thresholds (SRTs), both Gifford and Dorman [2012] and Morera et al. [2012] demonstrated 3-dB summation effects for 11 and 15 adult bimodal listeners, respectively.

Estimates of binaural squelch for bimodal listeners have been much less frequently reported than what has been typically reported in the literature for bilateral-implant recipients. Schafer et al. [2007] evaluated 3 studies [Tyler et al., 2002; Dunn et al., 2005; Morera et al., 2005] in a meta-analysis reporting squelch as the performance difference for the $\mathrm{CI}$ alone with noise directed to the hearing aid (HA) $\mathrm{S}_{0} \mathrm{~N}_{\mathrm{HA}}$ versus the bimodal condition in the same noise configuration $\left(\mathrm{S}_{0} \mathrm{~N}_{\mathrm{HA}}\right)$. Using this, they calculated a mean squelch estimate of 10.1 percentage points across the 3 studies, found to be not statistically significant. Using the same squelch calculation for squelch in an adaptive SRT, Morera et al. [2012] reported significant estimates of squelch ranging from 2.6 to $3.6 \mathrm{~dB}$, over two test sessions. They reported, however, that these estimates were largely driven by the results for 2 bimodal participants who demonstrated much better speech recognition performance with the HA over the implanted ear.

Bimodal listeners have demonstrated a similar magnitude of HS effect to bilateral-implant recipients, but with different estimates across ears, as expected, given the asymmetry in performance across the HA and CI ears. In a meta-analysis of 6 studies referencing the $\mathrm{CI}$ ear and 3 studies referencing the HA ear, Schafer et al. [2007] showed significant mean estimates of an HS of 17.4 percentage points for the implanted ear and 61.1 percentage points for the HA ear.

Unilateral-implant recipients with preserved hearing in the implanted ear (hearing preservation patients) have been shown to exhibit significant benefits for speech recognition with various noise sources [Dunn et al., 2010;
Gifford et al., 2010; Dorman et al., 2012; Gifford et al., 2013; Rader et al., 2013], horizontal-plane localization [Dunn et al., 2010] and preserved interaural time differences [Gifford et al., 2013]. Thus, there is some evidence that these patients have access to binaural cues. However, no published study has attempted to compare these patients to patients with bilateral CIs and patients with bimodal hearing regarding the availability of binaural cues.

The hypothesis underlying this project was that implant recipients with bilateral acoustic hearing would exhibit significantly greater summation and squelch than either bilateral CI patients or bimodal listeners (who do not have preserved hearing in the implanted ear). Our hypothesis was driven by our finding of access to interaural time difference cues [Gifford et al., 2013] in hearing preservation patients and the fact that interaural spectral 'mismatch', caused by disparate electrode insertion depths and electrode-to-neural interfaces for bilateral recipients, has been shown to negatively affect squelch and summation [Yoon et al., 2012]. Thus, the primary objective of the study was to examine the availability of binaural cues for adult bilateral CI recipients and bimodal listeners, both with and without preserved hearing in the implanted ear.

\section{Materials and Methods}

\section{Subjects}

Demographic information for the 81 study participants is shown in tables 1-3 for the 30 bilateral, 35 bimodal and 16 hearing preservation participants, respectively. Variables provided include age at testing, gender, implant type, experience with implants, aided Speech Intelligibility Index at $60 \mathrm{~dB}$ SPL as provided by the $\mathrm{Au}$ dioscan Verifit real-ear measures and Consonant Nucleus Consonant (CNC, [Peterson and Lehiste, 1962]) monosyllabic word recognition performance at $60 \mathrm{dBA}$. Of note is that not all of the implanted electrodes for the hearing preservation were specifically designed for hearing preservation purposes. Nevertheless, with minimally traumatic surgical techniques and patients having more preoperative hearing to potentially preserve, postoperatively we are going to be encountering more clinical patients with measurable, and aidable, hearing in the implanted ear. For the hearing preservation patients, the inclusion criteria specified audiometric thresholds of $80 \mathrm{~dB}$ hearing level or better, at $\leq 250 \mathrm{~Hz}$. This criterion was based on two factors. The first was the half-gain rule, as the maximum lowfrequency gain for most in-the-ear (ITE) HAs is approximately 40 $\mathrm{dB}$. The second basis for this criterion was that previous studies have shown that the majority of the electroacoustic stimulation- or bimodal-based benefit is derived from acoustic hearing at $\leq 250 \mathrm{~Hz}$ [Henry and Ricketts, 2003; Dawson et al., 2004; Zhang et al., 2010].

Participants ranged in age from 19 to 90 years with a mean age of 60.5 years. Of 30 bilateral participants, 26 received their implants in sequential surgeries. For all 81 participants, there was an average of 4.6 years (range $0.5-21.0$ years) experience with the first implant. For the sequential bilateral participants, the average ex- 
Table 1. Bilateral participant demographic information including age at testing, years of electric experience for the 1st and 2nd implants, implants, processors and CNC monosyllabic word recognition (\% correct) in the 1st CI, 2nd CI and in the bilateral condition

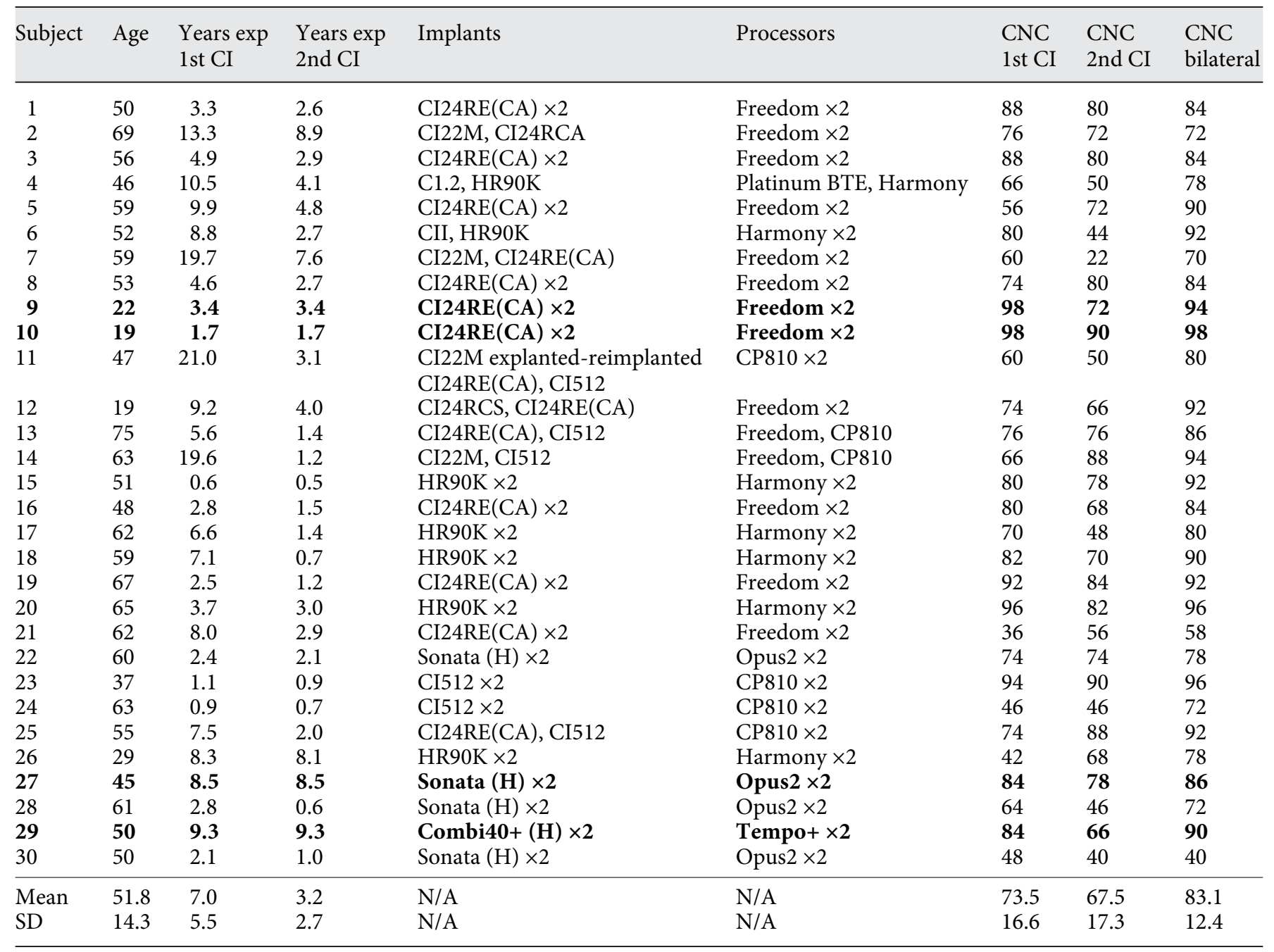

Participants who were simultaneously implanted are shaded in bold. $\mathrm{SD}=$ Standard deviation; Years exp = years of experience; $\mathrm{N} / \mathrm{A}=$ not applicable.

perience with the second implant was 3.2 years (range $0.5-9.3$ years) with a mean difference between the two implants of 4.4 years (range 0.1-18.4 years). Though the CNC monosyllabic-word recognition scores are not demographic in nature, they were included here to characterize outcomes for what is generally considered the most commonly reported metric for English-speaking recipients. More detail will be provided for CNC monosyllabic-word recognition in the Results section.

Individual and mean audiograms for the nonimplanted ears of the unilateral-implant recipients, with and without preserved acoustic hearing in the implanted ear, are shown in figure 1a. Figure $1 \mathrm{~b}$ displays individual and mean postoperative audiograms for the implanted ear for the participants with preserved acoustic hearing in the implanted ear. Audiograms were obtained for all participants immediately prior to experimentation.

Availability of Binaural Cues for CI

Recipients and Bimodal Listeners

\section{Methods}

Speech perception was assessed during one or two visits, depending upon listener preference, using recorded stimuli presented in a sound-treated booth at a calibrated level of $60 \mathrm{dBA}$. For the 3 participants preferring to participate over two test sessions, the period between sessions was between 1 day and 1 week. Participants used their everyday CI programs and were not permitted to manipulate settings during testing. For Nucleus ${ }^{\circledR}$ implant recipients, all participants used the 'EVERYDAY' setting which makes use of the default directional microphone (mic) setting with the addition of Autosensitivity and Adaptive Dynamic Range Optimization [Dawson et al., 2004]. Test conditions for the Speech-inNoise (SIN) testing included speech at $0^{\circ}$ with noise presented at $0^{\circ}\left(\mathrm{S}_{0} \mathrm{~N}_{0}\right), 90^{\circ}\left(\mathrm{S}_{0} \mathrm{~N}_{90}\right)$ and $270^{\circ}\left(\mathrm{S}_{0} \mathrm{~N}_{270}\right)$. All three listening conditions were completed for each individual ear as well as for the bi- 
Table 2. Bimodal participant demographic information including age at testing, years of electric experience, implant, processor, aided Speech Intelligibility Index (SII) at $60 \mathrm{~dB}$ SPL and CNC monosyllabic word recognition (\% correct) in the HA, CI and bimodal conditions

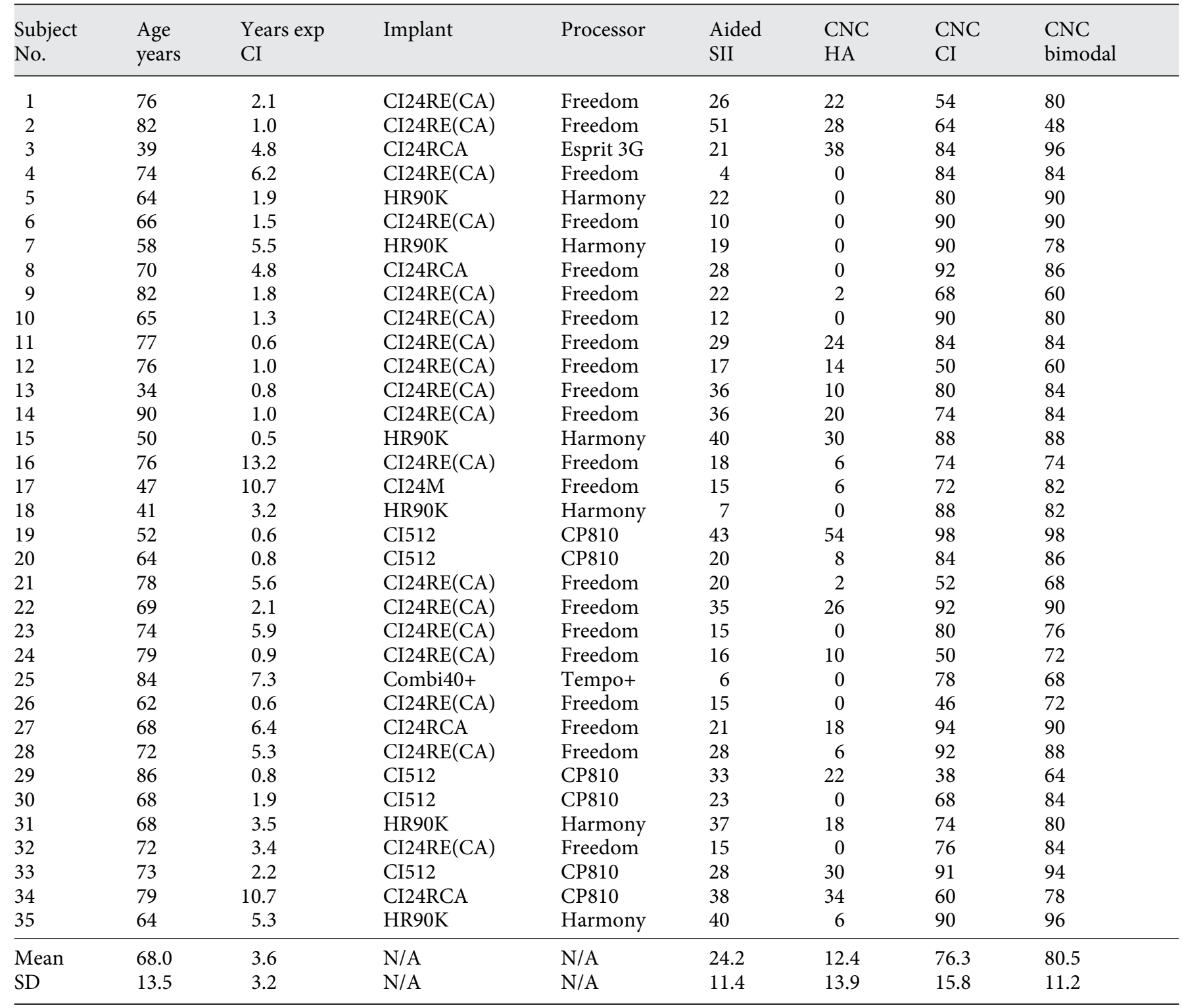

lateral, best-aided condition (bilateral, bimodal or CI + bilateral HAs).

For unilateral-implant recipients wearing HAs in one or both ears, HA audibility was verified for $60-\mathrm{dB}-\mathrm{SPL}$ speech immediately prior to experimentation using real-ear measurements with NAL-NL1 prescriptive targets [Dillon et al., 1998]. Participants for whom HAs were undershooting target audibility by $>5 \mathrm{~dB}$ at one or more frequencies had their HAs reprogrammed to match NAL-NL1 targets. For participants whose own HAs could not be adjusted due to lack of reserve gain or incompatibility with NOAH programming software, laboratory stock HAs (Phonak Naida III UP with deactivated Sound Recover, i.e. non- linear frequency compression) were programmed and used for testing purposes. This occurred for 6 of the bimodal subjects $(18,23,24,25,32$ and 33$)$. For these 6 , testing was only completed with the stock HAs programmed to NAL-NL1 target audibility.

For BKB-SIN, the SNR-50 - or the SNR at which approximately $50 \%$ correct performance would be expected - was recorded for each condition. Two paired lists (e.g. 1A/B and 2A/B) were presented for each listening condition with the average SNR-50 across the paired lists reported as mean performance per participant. For the AzBio sentences at $+5 \mathrm{~dB}$ SNR, performance was recorded in percent words correct. Two 20-sentence lists
60 


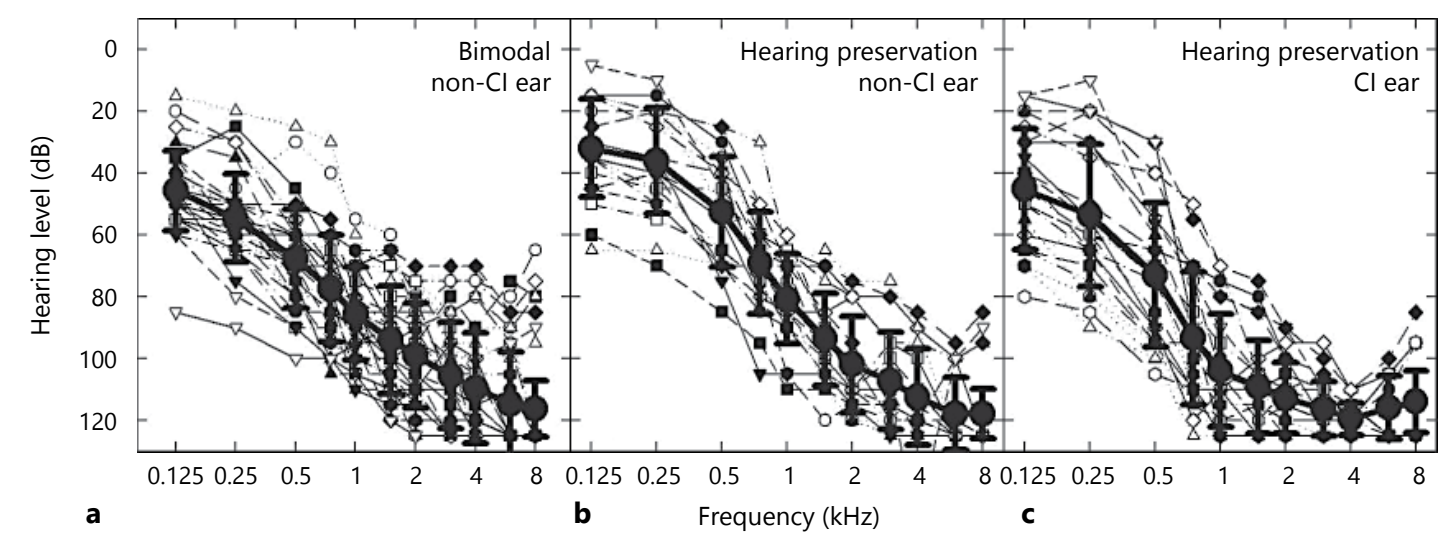

Fig. 1. Individual and mean audiometric thresholds (in $\mathrm{dB}$ ) obtained on the day of testing for the nonimplanted ears of the bimodal and hearing preservation patients as well as the implanted ear of the hearing preservation patients. Error bars represent \pm 1 standard deviation.

Table 3. Hearing preservation participant demographic information including age at testing, years of electric experience, implant, processor, aided Speech Intelligibility Index (SII) at $60 \mathrm{~dB}$ SPL in both the implanted and nonimplanted ears and CNC monosyllabic word recognition (\% correct) in the following conditions: HA in implanted ear (ipsi HA), HA in nonimplanted ear (contra HA), CI only, CI + ipsi HA, CI + contra HA and CI + bilateral HAs

\begin{tabular}{|c|c|c|c|c|c|c|c|c|c|c|c|c|}
\hline $\begin{array}{l}\text { Subject } \\
\text { No. }\end{array}$ & $\begin{array}{l}\text { Age } \\
\text { years }\end{array}$ & $\begin{array}{l}\text { Years } \\
\exp C I\end{array}$ & Implant & Processor & $\begin{array}{l}\text { Aided SII } \\
\text { non-CI ear }\end{array}$ & $\begin{array}{l}\text { Aided SII } \\
\text { CI ear }\end{array}$ & $\begin{array}{l}\text { CNC } \\
\text { ipsi HA }\end{array}$ & $\begin{array}{l}\text { CNC } \\
\text { contra HA }\end{array}$ & $\begin{array}{l}\text { CNC CI } \\
\text { only }\end{array}$ & $\begin{array}{l}\text { CNC CI + } \\
\text { ipsi HA }\end{array}$ & $\begin{array}{l}\text { CNC CI + } \\
\text { contra HA }\end{array}$ & $\begin{array}{l}\mathrm{CNC} \mathrm{CI}+ \\
\text { bilateral HA }\end{array}$ \\
\hline 1 & 71 & 1.1 & Hybrid L24 & Hybrid Freedom & 31 & 24 & 24 & 26 & 68 & 82 & 74 & 78 \\
\hline 2 & 70 & 4.7 & CI24RCA & Freedom & 18 & 6 & 0 & 10 & 94 & 90 & 98 & 94 \\
\hline 3 & 69 & 1.0 & Hybrid S8 & Hybrid Freedom & 57 & 44 & 16 & 50 & 42 & 74 & 78 & 82 \\
\hline 4 & 52 & 0.7 & CI512 & CP810 & 46 & 9 & 6 & 54 & 98 & 96 & 98 & 98 \\
\hline 5 & 49 & 4.5 & CI24RE(CA) & Freedom & 30 & 10 & 4 & 4 & 90 & 90 & 96 & 98 \\
\hline 6 & 79 & 1.7 & CI24RE(CA) & Freedom & 12 & 16 & 0 & 26 & 80 & 92 & 96 & 94 \\
\hline 7 & 61 & 2.1 & Hybrid L24 & Hybrid Freedom & 32 & 34 & 21 & 48 & 76 & 94 & 90 & 88 \\
\hline 8 & 61 & 1.0 & CI512 & CP810 & 19 & 6 & 10 & 30 & 84 & 82 & 80 & 84 \\
\hline 9 & 45 & 1.4 & Sonata $(\mathrm{H})$ & Opus2 & 30 & 6 & 2 & 44 & 82 & 84 & 82 & 84 \\
\hline 10 & 53 & 4.0 & Hybrid S8 & Hybrid Freedom & 38 & 34 & 28 & 36 & 44 & 60 & 62 & 80 \\
\hline 11 & 58 & 6.4 & CI24RCA & CP810 & 31 & 16 & 18 & 24 & 82 & 86 & 84 & 86 \\
\hline 12 & 52 & 2.0 & Hybrid S8 & Hybrid Freedom & 32 & 12 & 12 & 48 & 62 & 58 & 86 & 86 \\
\hline 13 & 34 & 4.1 & CI24RCA & Esprit 3G & 35 & 9 & 2 & 28 & 80 & 84 & 88 & 90 \\
\hline 14 & 52 & 1.4 & Hybrid L24 & Hybrid Freedom & 44 & 36 & 26 & 52 & 76 & 90 & 88 & 88 \\
\hline 15 & 77 & 0.6 & Sonata $(\mathrm{H})$ & Opus2 & 22 & 12 & 0 & 14 & 48 & 56 & 46 & 56 \\
\hline 16 & 83 & 0.9 & CI422 & CP810 & 29 & 15 & 0 & 12 & 26 & 42 & 40 & 46 \\
\hline Mean & 58.9 & 2.4 & $\mathrm{~N} / \mathrm{A}$ & N/A & 31.6 & 18.1 & 10.6 & 31.6 & 70.8 & 78.8 & 80.4 & 83.3 \\
\hline $\mathrm{SD}$ & 12.5 & 1.8 & N/A & $\mathrm{N} / \mathrm{A}$ & 11.2 & 12.4 & 10.23 & 16.1 & 20.7 & 16.1 & 17.4 & 14.0 \\
\hline
\end{tabular}

were run for each listening condition with the average performance across the two lists recorded for each participant. Listening conditions were counterbalanced across participants in each listener group with the list numbers chosen in a quasi-random manner.

In addition to the SIN testing, CNC word recognition was also assessed for all 81 subjects for each ear individually as well as in the bilateral, best-aided condition. For the hearing preservation subjects, additional listening conditions were tested including a $\mathrm{HA}$ in the implanted ear (ipsilateral HA), a CI plus an ipsilateral HA, a CI plus a contralateral HA (commonly termed the 'bimodal' condition), as well as a CI plus bilateral HAs (i.e. bilateral best-aided). All speech stimuli were presented at a calibrated level of $60 \mathrm{dBA}$. 


\section{Results}

\section{CNC Word Recognition}

As shown in tables 1-3, CNC word recognition performance was obtained for all 81 participants in each individual ear condition and the bilateral, best-aided condition. Mean 'implant only' performance across all 81 participants was $72.3 \%$ with a range of $26-98 \%$ correct. $^{1}$ Considering the poorer-hearing ear for all participants, mean $\mathrm{CNC}$ word recognition was $35.3 \%$ with a range of 0-90\% with the lowest scores belonging to the unilateralimplant recipients' nonimplanted ears. Considering the bilateral, best-aided condition (i.e. all devices, both ears) for all 81 participants, mean $\mathrm{CNC}$ word recognition was $82.0 \%$ with a range of $40-98 \%$ correct.

For $\mathrm{CNC}$ word recognition, a two-way, repeated-measures analysis of variance (ANOVA) was completed with the subject group (bimodal, bilateral and hearing preservation groups) and listening condition (better ear, poorer ear and bilateral best-aided) as variables. For this analysis, the better-hearing ear for the hearing preservation patients was defined as the implant plus the ipsilateral HA (see table 3 ) and the bilateral best-aided condition included both ears with all available devices. In other words, the bilateral best-aided condition included the implant plus bilateral HAs for the hearing preservation subjects. The ANOVA revealed a significant effect of subject group $\left[\mathrm{F}_{(2,78)}=21.1, \mathrm{p}<0.001\right]$, listening condition $\left[\mathrm{F}_{(2,78)}=\right.$ 437.7, $\mathrm{p}<0.001]$ and a significant interaction $\left[\mathrm{F}_{(4)}=65.0\right.$, $\mathrm{p}<0.001]$. Post hoc multiple comparisons using the HolmSidak test revealed no significant difference across the 3 subject groups for the better-hearing ear ( $\mathrm{p}>0.26$ for all comparisons). Considering the bilateral best-aided condition, there was also no significant difference across the 3 groups ( $\mathrm{p}>0.24$ for all comparisons). Not unexpectedly, however, there was a significant difference for the poorer-

\footnotetext{
${ }^{1}$ For most sequentially implanted recipients, the better-performing ear was the first implanted ear. For 20 of the 26 of the sequentially implanted bilateral recipients ( $77 \%$ of the study bilateral population), the first implanted ear was the better-performing ear (i.e. subjects 1-7, 11-13, 15-20, 22-24, 28 and 29). Out of these 20 participants, 3 (6, 7 and 17) exhibited statistically significant CNC word recognition performance for the 1st implanted ear based on a binomial distribution model [Thornton and Raffin, 1978]. Of the 6 sequentially implanted bilateral recipients for whom the 1st implanted ear did not exhibit the best performance (i.e. subjects 5, 8, 14, 21, 25 and 26), 3 demonstrated a significantly poorer performance with the 1st implanted ear using the binomial distribution statistic [Thornton and Raffin, 1978]. All sequentially implanted patients reported having first implanted their poorer-hearing ear on the basis of preoperative audiometric thresholds and/or speech recognition performance. Except for the 3 subjects demonstrating significantly poorer performance with the 1st implanted ear, all of them reported a preference for the 1st implanted ear.
}

hearing ear, with the bilateral subjects achieving significantly higher levels of word recognition than both the bimodal $(\mathrm{t}=14.7, \mathrm{p}<0.001)$ and the hearing preservation subjects $(\mathrm{t}=7.0, \mathrm{p}<0.001)$. The hearing preservation subjects scored significantly higher than the bimodal subjects $(\mathrm{t}=4.7, \mathrm{p}<0.001)$ for the poorer-hearing ear which reflects lower (i.e. better) audiometric thresholds in the nonimplanted ears for the hearing preservation participants (fig. 1) and associated higher (i.e. better) aided Speech Intelligibility Index values (see tables 2, 3).

Summation for $\mathrm{CNC}$ word recognition can be estimated by subtracting the score for the better-hearing ear from the bilateral, best-aided score. Summation estimates were 6.1, 4.3 and 4.4 percentage points for the bilateral, bimodal and hearing preservation subjects, respectively. Statistical analysis was completed for summation estimates across subject groups. A Kruskal-Wallis ANOVA on ranks was completed as the assumption of normality was not met. There was no significant difference $\left[\mathrm{H}_{(2)}=1.6\right.$, $\mathrm{p}=0.45$ ] across the 3 subject groups for summation observed with $\mathrm{CNC}$ word recognition in quiet.

\section{Speech-in-Noise: $S_{0} N_{0}$}

With reference to the BKB-SIN scores shown in figure 2a, mean SNR-50 for the better-hearing ear was $6.8 \mathrm{~dB}$ for bilateral, $7.2 \mathrm{~dB}$ for bimodal and $7.4 \mathrm{~dB}$ for hearing preservation subjects. Mean SNR-50 for the poorer-hearing ear was $10.0 \mathrm{~dB}$ for bilateral, $19.3 \mathrm{~dB}$ for bimodal and 15.0 $\mathrm{dB}$ for hearing preservation subjects. For the best-aided condition, mean SNR-50 was $5.8 \mathrm{~dB}$ for bilateral, $6.3 \mathrm{~dB}$ for bimodal and $5.3 \mathrm{~dB}$ for hearing preservation subjects. A two-way ANOVA was completed with listening condition and subject group as the variables. The analysis revealed a significant main effect of listening condition $\left[\mathrm{F}_{(2)}=129.8, \mathrm{p}<0.001\right]$, subject group $\left[\mathrm{F}_{(2)}=23.5, \mathrm{p}<\right.$ $0.001]$ and a significant interaction $\left[\mathrm{F}_{(2)}=17.1, \mathrm{p}<0.001\right]$. Post hoc analysis using the Holm-Sidak statistic showed no difference across the 3 subject groups for either the better-hearing ear or the best-aided condition ( $p>0.11$ for all comparisons). There were significant differences across the subject groups for the poorer-hearing ear with all subject groups being significantly different from one another ( $\mathrm{p}<0.001$ in all cases).

With reference to the AzBio sentence recognition at $+5 \mathrm{~dB}$ SNR (fig. $2 \mathrm{~b}$ ), mean performance (in percent correct) for the better-hearing ear was $56.8 \%$ for bilateral, $49.2 \%$ for bimodal and $60.1 \%$ for hearing preservation subjects. Mean performance for the poorer-hearing ear was $36.1 \%$ for bilateral, $5.7 \%$ for bimodal and $16.7 \%$ for hearing preservation subjects. For the best-aided condi- 


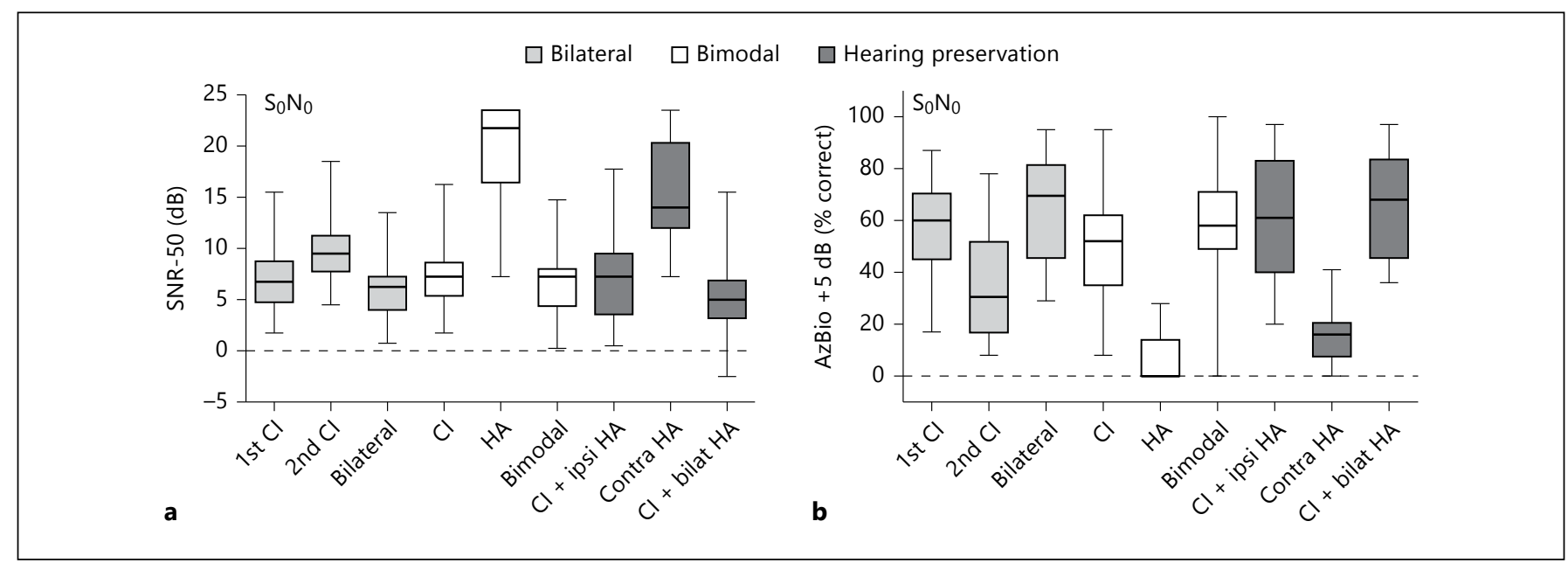

Fig. 2. Box and whisker plots for BKB-SIN (SNR-50; a) and AzBio at $+5 \mathrm{~dB}(\%$ correct; $\boldsymbol{b})$ for the $\mathrm{S}_{0} \mathrm{~N}_{0}$ listening condition. The box extends from the 25 th to the 75 th percentile with the horizontal line in the middle representing the median. The whiskers extend from the minimum to the maximum value for all individual data thus displaying the range of scores for any given condition.

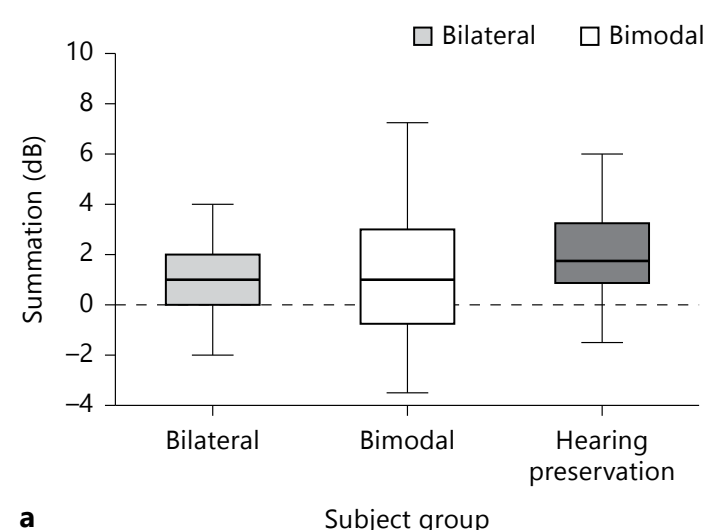

a

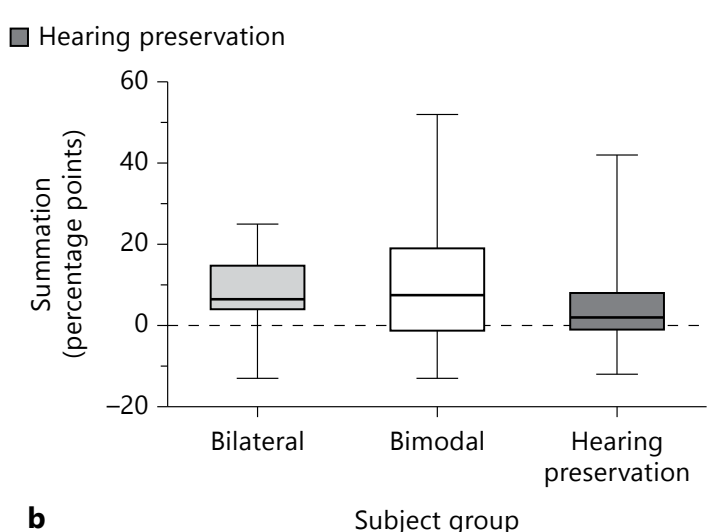

b

Subject group
Fig. 3. Box and whisker plots for BKB-SIN (in dB; a) and AzBio at $+5 \mathrm{~dB}$ (in percentage points; b). The box extends from the 25 th to the 75 th percentile with the horizontal line in the middle repre-

tion, mean performance was $65.5 \%$ for bilateral, $58.6 \%$ for bimodal and $65.9 \%$ for hearing preservation subjects. As with the BKB-SIN results in the $\mathrm{S}_{0} \mathrm{~N}_{0}$ condition, a twoway ANOVA was completed with listening condition and subject group as the variables. The analysis revealed a significant main effect of listening condition $\left[\mathrm{F}_{(2,231)}=116.2\right.$, $\mathrm{p}<0.001]$, subject group $\left[\mathrm{F}_{(2,2)}=15.9, \mathrm{p}<0.001\right]$ and a significant interaction $\left[\mathrm{F}_{(2,4)}=4.4, \mathrm{p}=0.002\right]$. Holm-Sidak post hoc analysis showed no difference across the 3 groups for either the better-hearing ear or the best-aided condition ( $p>0.10$ for all comparisons). There were sig- senting the median. The whiskers extend from the minimum to the maximum value for all individual data thus displaying the range of scores for any given condition. nificant differences across the groups for the poorerhearing ear, with all 3 groups being significantly different from one another (bilateral vs. bimodal, $\mathrm{p}<0.001$; bilateral vs. hearing preservation, $\mathrm{p}=0.001$; bimodal vs. hearing preservation, $\mathrm{p}=0.04$ ).

\section{Summation}

Estimates of summation were gathered from figure 2 as the difference between the better-hearing ear and bestaided condition. Box and whisker plots are shown in figure 3. For BKB-SIN (fig. 3a), mean summation was 1.0, 


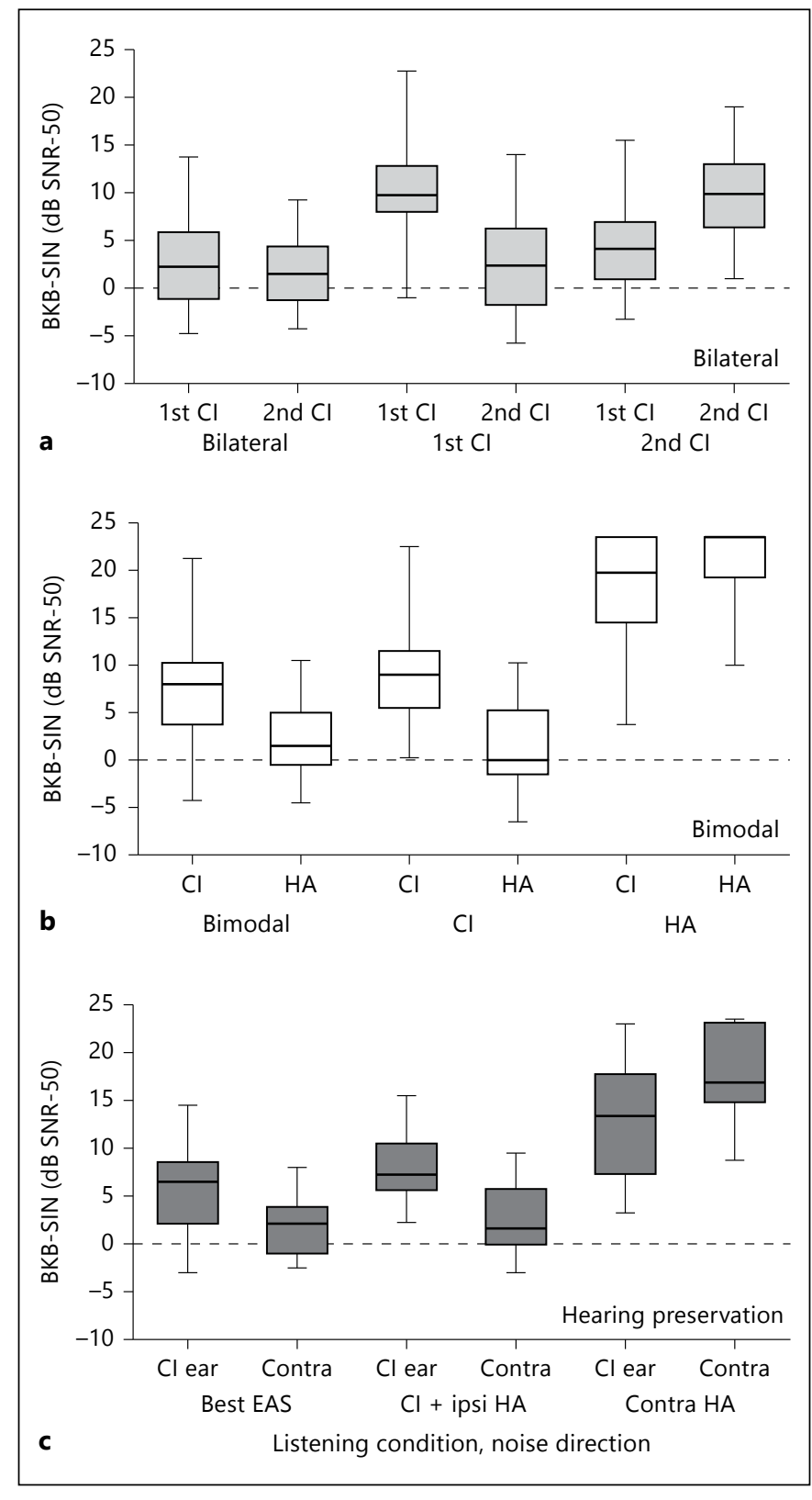

Fig. 4. Box and whisker plots for BKB-SIN (SNR-50) for the bilateral (a), bimodal (b) and hearing preservation subjects (c) for the spatially separated listening conditions with $\mathrm{S}_{0} \mathrm{~N}_{90}$ and $\mathrm{S}_{0} \mathrm{~N}_{270}$.

0.9 and $1.9 \mathrm{~dB}$ for the bilateral, bimodal and hearing preservation participants, respectively. Individual estimates of summation ranged from -3.5 to $7.3 \mathrm{~dB}$ for bilateral, -2 to $4 \mathrm{~dB}$ for bimodal and -1.5 to $6.0 \mathrm{~dB}$ for hearing preservation participants. A one-way ANOVA revealed no difference across the subjects groups in terms of summation effects $\left(\mathrm{F}_{(2)}=1.7, \mathrm{p}=0.18\right)$. For AzBio sentence rec- ognition at $+5 \mathrm{~dB}$ (fig. $3 \mathrm{~b}$ ), mean summation was $8.5,9.5$ and 5.4 percentage points for the bilateral, bimodal and hearing preservation subjects, respectively. Individual estimates of summation ranged from -13 to 52 percentage points for bilateral, -13 to 25 percentage points for bimodal and -12 to 42 percentage points for hearing preservation participants. As with BKB-SIN, a one-way ANOVA revealed no difference across the groups ( $\mathrm{F}=$ $0.62, \mathrm{p}=0.54)$.

\section{Speech-in-Noise: Spatially Separated Listening Conditions}

Figure 4 displays box and whisker plots for BKB-SIN scores (SNR-50) for the bilateral, bimodal and hearing preservation subjects for the spatially separated listening conditions $\left(\mathrm{S}_{0} \mathrm{~N}_{90}\right.$ and $\left.\mathrm{S}_{0} \mathrm{~N}_{270}\right)$. Figure 5 displays the same box and whisker plots as figure 4 but for AzBio sentence recognition at $+5 \mathrm{~dB}$ SNR. With the data shown in figures 2, 4 and 5, we are able to calculate estimates of HS, SRM and squelch.

Head Shadow

Estimates of HS were calculated as follows:

Bilateral Subjects

$\mathrm{HS}$ for 1 st $\mathrm{CI}=$ score for 1 st $\mathrm{CI}$ (noise to 2 nd CI) score for 1st CI (noise to 1st CI).

HS for 2 nd CI $=$ score for 2 nd CI (noise to 1 st CI) score for 2nd CI (noise to 2nd CI).

Bimodal Subjects

HS for CI ear = score for CI ear (noise to HA ear) score for CI ear (noise to CI ear).

HS for HA ear = score for HA ear (noise to CI ear) score for HA ear (noise to HA ear).

Hearing Preservation Subjects

HS for CI ear = score for CI ear (noise to non-CI ear) score for CI ear (noise to CI ear).

HS for non-CI ear = score for non-CI ear (noise to CI ear) - score for non-CI ear (noise to non-CI ear).

Estimates of HS are shown in figure 6 for BKB-SIN and AzBio at $+5 \mathrm{~dB}$ SNR, respectively. For BKB-SIN, mean $\mathrm{HS}$ for the bilateral CI recipients was 7.6 and 5.3 $\mathrm{dB}$ for the 1 st and 2 nd implanted ears, respectively. Mean HS for the bimodal listeners was 7.6 and $3.3 \mathrm{~dB}$ for the CI and HA ears, respectively. Mean HS for the hearing preservation subjects was 5.0 and $4.8 \mathrm{~dB}$ for the $\mathrm{CI}$ and nonCI ears, respectively. A two-way ANOVA with subject 


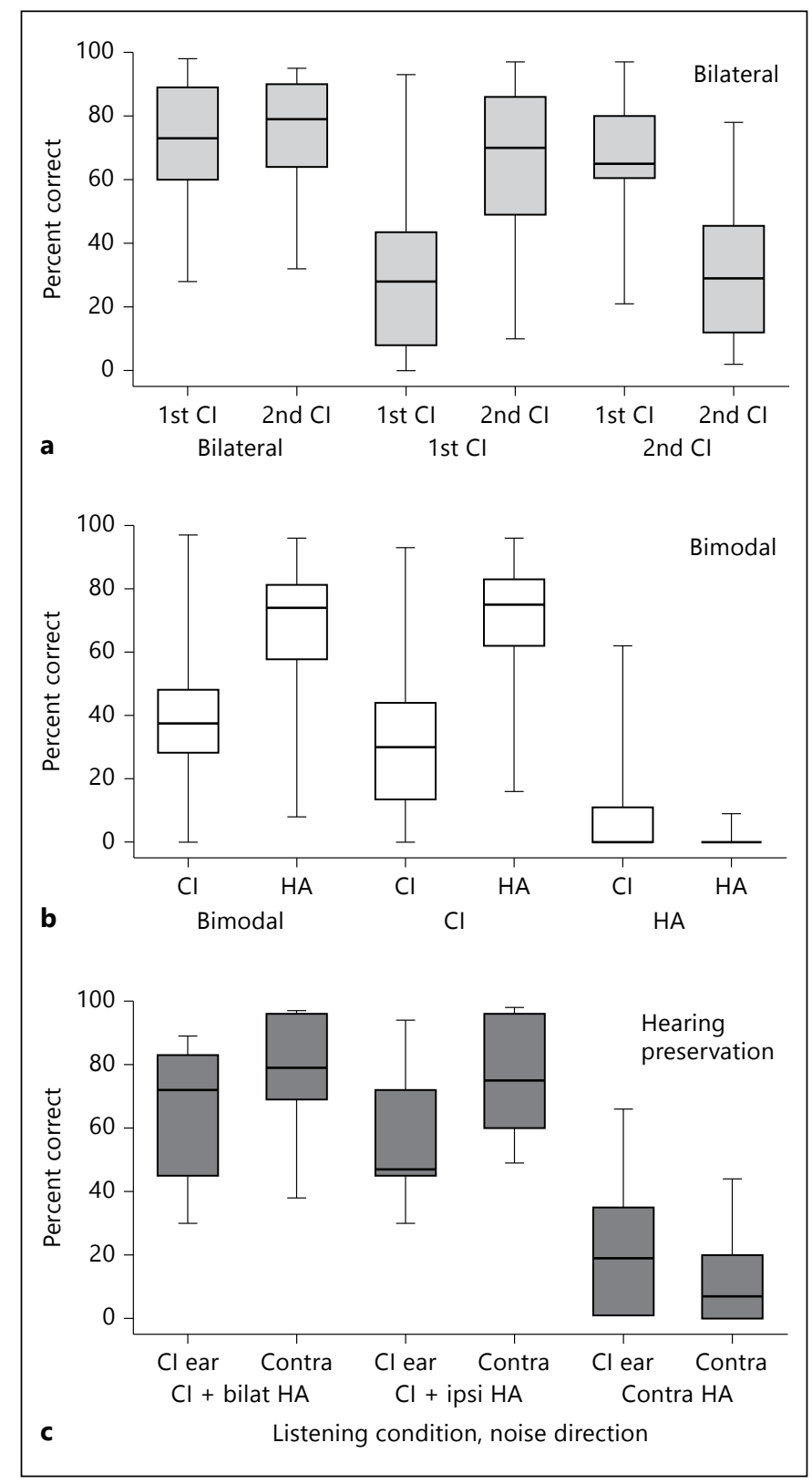

Fig. 5. Box and whisker plots for AzBio sentences at $+5 \mathrm{~dB}$ (percent correct) for the bilateral (a), bimodal (b) and hearing preservation subjects (c) for the spatially separated listening conditions with $\mathrm{S}_{0} \mathrm{~N}_{90}$ and $\mathrm{S}_{0} \mathrm{~N}_{270}$.

group and listening condition (poorer vs. better ear) revealed no effect of subject group $\left[\mathrm{F}_{(2,231)}=1.2, \mathrm{p}=0.30\right]$, a significant effect of listening condition $\left[\mathrm{F}_{(2,2)}=7.7, \mathrm{p}=\right.$ $0.006]$ and no interaction $\left[\mathrm{F}_{(2,2)}=2.4, \mathrm{p}=0.09\right]$. Thus there was no difference in HS across the subject groups, but estimates were significantly greater for the betterhearing ear.

Availability of Binaural Cues for CI

Recipients and Bimodal Listeners
For AzBio at $+5 \mathrm{~dB}$ SNR, mean HS for the bilateral CI recipients was 34.7 and 32.9 percentage points for the 1st and 2nd implanted ears, respectively. Mean HS for the bimodal listeners was 36.6 and 7.1 percentage points for the $\mathrm{CI}$ and HA ears, respectively. Mean HS for the hearing preservation subjects was 22.0 and 11.8 percentage points for the CI and non-CI ears, respectively. A two-way ANOVA completed with subject group and listening condition revealed a significant effect of subject group $\left[\mathrm{F}_{(2,231)}=8.7\right.$, $\mathrm{p}<0.001]$, a significant effect of listening condition $\left[\mathrm{F}_{(2,2)}=\right.$ $14.0, \mathrm{p}<0.001]$ and a significant interaction $\left[\mathrm{F}_{(2,2)}=8.2\right.$, $\mathrm{p}<0.001]$. Holm-Sidak post hoc analysis revealed that the HS estimates were significantly greater for the bilateral-implant recipients than for the bimodal $(\mathrm{t}=3.4, \mathrm{p}=0.001)$ and hearing preservation $(\mathrm{t}=3.8, \mathrm{p}=0.0002)$ participants. There was no significant difference across the 3 subject groups for the better-hearing ear ( $\mathrm{p}>0.05$ for all comparisons). There were significant differences across the subject groups for the poorer-hearing ear with each group being significantly different from the others (bilateral vs. bimod$\mathrm{al}, \mathrm{p}=0.03$; bilateral vs. hearing preservation, $\mathrm{p}=0.03$; bimodal vs. hearing preservation, $\mathrm{p}=0.01$ ).

Spatial Release from Masking

Estimates of SRM were calculated as follows:

Bilateral Subjects

SRM for 1 st CI = score for 1 st CI (noise to 2 nd CI) score for 1 st $\mathrm{CI}$ (noise at $0^{\circ}$ ).

SRM for 2nd CI = score for 2nd CI (noise to 1st CI) score for 2 nd CI (noise at $0^{\circ}$ ).

Bimodal Subjects

SRM for CI ear $=$ score for CI ear (noise to HA ear) score for $\mathrm{CI}$ ear (noise at $0^{\circ}$ ).

SRM for HA ear = score for HA ear (noise to CI ear) score for HA ear (noise at $0^{\circ}$ ).

Hearing Preservation Subjects

SRM for $\mathrm{CI}$ ear = score for CI ear (noise to non-CI ear) - score for CI ear (noise at $0^{\circ}$ ).

SRM for non-CI ear $=$ score for non-CI ear (noise to CI ear) - score for non-CI ear (noise at $0^{\circ}$ ).

For All Subject Groups, SRM in the Best-Aided Condition

SRM for best-aided = score for best-aided condition (noise to poorer ear) - score for best-aided condition (noise at $0^{\circ}$ ). 


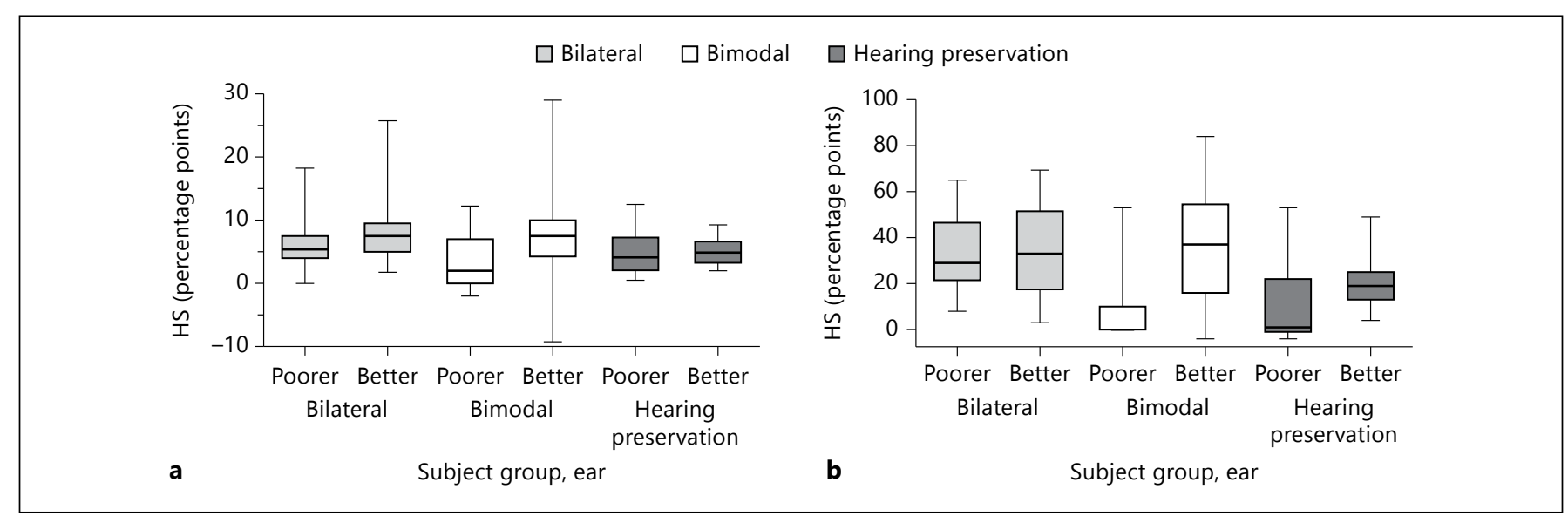

Fig. 6. Box and whisker plots displaying estimates of HS for BKB-SIN (in $\mathrm{dB}$; a) and AzBio at $+5 \mathrm{~dB}$ SNR (in percentage points; b) for the poorer ear, better ear and best-aided conditions.

Fig. 7. Box and whisker plots displaying estimates of SRM for BKB-SIN (in dB; a) and $\mathrm{AzBio}$ at $+5 \mathrm{~dB}$ SNR (in percentage points; b) for the best-aided condition.

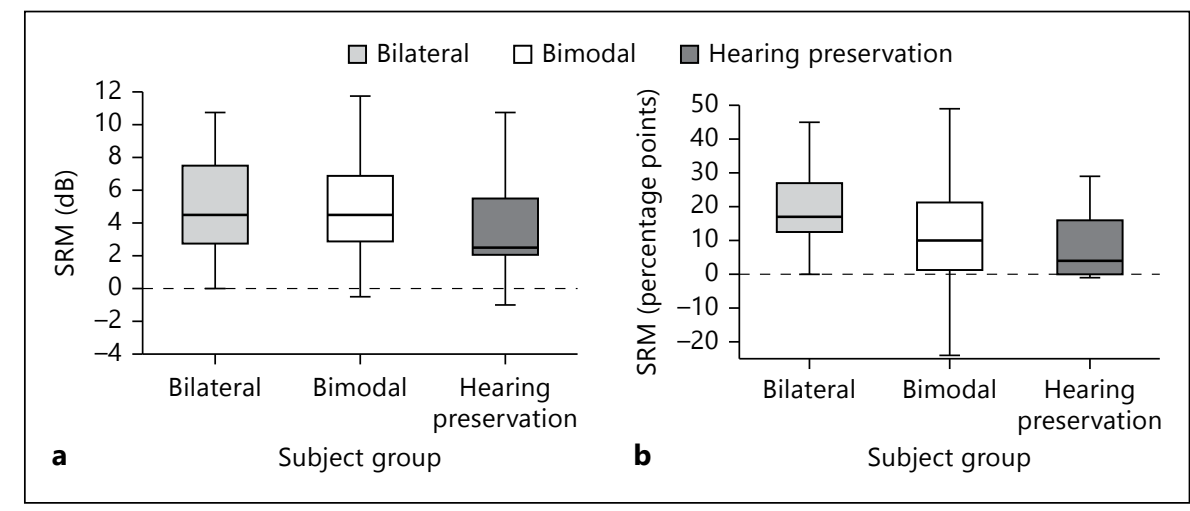

Estimates of SRM in the best-aided condition are shown in figure 7 for BKB-SIN and AzBio at $+5 \mathrm{~dB}$ SNR, respectively. For BKB-SIN, mean SRM for the bilateral CI recipients was 3.5 and $3.8 \mathrm{~dB}$ for the 1 st and 2 nd implanted ears, respectively, and $5.1 \mathrm{~dB}$ for the bilateral best-aided condition. Mean SRM for the bimodal listeners was 5.7 and $1.5 \mathrm{~dB}$ for the $\mathrm{CI}$ and HA ears, respectively, and 4.9 $\mathrm{dB}$ for the bimodal best-aided condition. Mean SRM for the hearing preservation subjects was 4.0 and $2.1 \mathrm{~dB}$ for the $\mathrm{CI}$ and non-CI ears, respectively, and $3.8 \mathrm{~dB}$ for the best-aided condition ( $\mathrm{CI}+$ bilateral HA). A one-way ANOVA completed for SRM observed revealed no effect of subject group for the better-hearing ear $\left[\mathrm{F}_{(2)}=1.4, \mathrm{p}=\right.$ $0.25]$ or for the best-aided condition $\left[\mathrm{F}_{(2)}=1.3, \mathrm{p}=0.29\right.$ ], but a significant effect of group for the poorer-hearing ear $\left[\mathrm{F}_{(2)}=11.1, \mathrm{p}<0.001\right]$. For the poorer-hearing ear, post hoc testing (Holm-Sidak) revealed that the SRM of bimodal subjects was significantly poorer than that of both bilateral $(\mathrm{t}=4.5, \mathrm{p}=0.00002)$ and hearing preservation $(t=3.0, p=0.004)$ subjects, but that the bilateral and hearing preservation groups were not different $(p=0.49)$.

For AzBio at $+5 \mathrm{~dB}$ SNR, mean SRM for the bilateral CI recipients was 20.9 and 16.3 percentage points for the 1 st and 2nd implanted ears, respectively, and 20.4 percentage points for the best-aided condition. Mean SRM for the bimodal listeners was 19.9 and 2.7 percentage points for the CI and HA ears, respectively, and 14.1 percentage points for the best-aided condition. Mean SRM for the hearing preservation subjects was 8.4 and 11.5 percentage points for the CI and non-CI ears, respectively, and 10.0 percentage points for the best-aided condition. A one-way ANOVA completed for SRM observed revealed no effect of subject group for the better-hearing ear $\left[\mathrm{F}_{(2)}=2.2, \mathrm{p}=0.12\right]$ or for the best-aided condition $\left[\mathrm{F}_{(2)}=\right.$ $0.14, p=0.87]$, but a significant effect of group for the poorer-hearing ear $\left[\mathrm{F}_{(2)}=13.3, \mathrm{p}<0.001\right]$. For the poorer- 


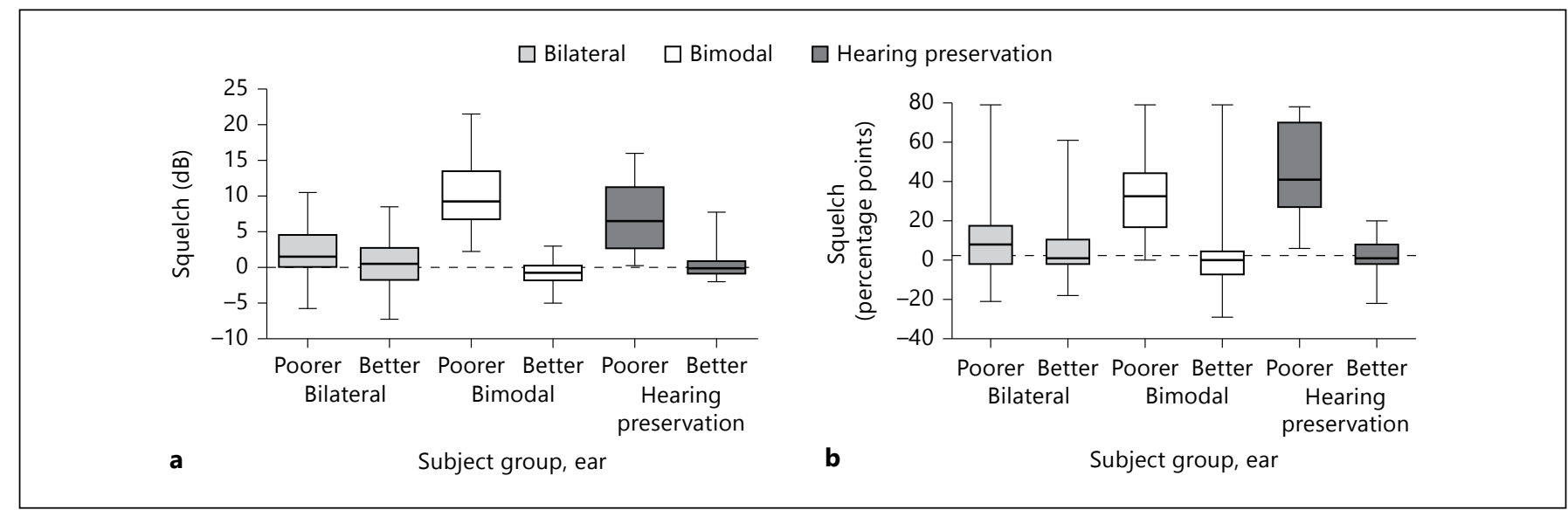

Fig. 8. Box and whisker plots displaying estimates of SRM for BKB-SIN (in dB; a) and AzBio at $+5 \mathrm{~dB}$ SNR (in percentage points; b) for the best-aided condition.

hearing ear, Holm-Sidak post hoc analysis revealed that the SRM estimates were significantly greater for the bilateral-implant recipients than for both the bimodal $(t=5.2$, $\mathrm{p}<0.0001)$ and the hearing preservation $(\mathrm{t}=2.2, \mathrm{p}=$ 0.049) participants.

\section{Squelch}

Estimates of squelch were calculated as follows:

Bilateral Subjects

Squelch for 1st CI = score for bilateral CI (noise to 2nd CI) - score for 1st CI (noise to 2nd CI).

Squelch for $2 \mathrm{nd} \mathrm{CI}=$ score for bilateral CI (noise to 1 st CI) - score for 2nd CI (noise to 1st CI).

Bimodal Subjects

Squelch for CI ear = score for bimodal (noise to HA ear) - score for CI ear (noise to HA ear).

Squelch for HA ear = score for bimodal (noise to CI ear) - score for HA ear (noise to CI ear).

Hearing Preservation Subjects

Squelch for CI ear = score for best aided (noise to nonCI ear) - score for CI ear (noise to non-CI ear).

Squelch for non-CI ear $=$ score for best aided (noise to CI ear) - score for non-CI ear (noise to CI ear).
Squelch estimates for BKB-SIN and AzBio at $+5 \mathrm{~dB}$ are shown in Figures $8 \mathrm{a}$ and b, respectively. For BKB-SIN, because a lower score represents better performance, squelch estimates obtained via the above-referenced equations yielded negative numbers for positive squelch and positive numbers for negative squelch. For ease of reporting and interpretation, all squelch estimates for the BKBSIN metric have been inverted, such that positive squelch will be reported as positive numbers and vice versa. For BKB-SIN, mean squelch for the bilateral CI recipients was 0.9 and $2.3 \mathrm{~dB}$ for the 1 st and 2 nd implanted ears, respectively. Mean squelch for the bimodal listeners was -0.7 and $10.4 \mathrm{~dB}$ for the $\mathrm{CI}$ and HA ears, respectively. Mean squelch for the hearing preservation subjects was 0.5 and $7.2 \mathrm{~dB}$ for the $\mathrm{CI}$ and non-CI ears, respectively. A two-way ANOVA completed with subject group and listening condition revealed an effect of subject group $\left[\mathrm{F}_{(2)}=12.3, \mathrm{p}<\right.$ $0.001]$, listening condition $\left[\mathrm{F}_{(1)}=99.9, \mathrm{p}<0.001\right]$ and a significant interaction $\left[\mathrm{F}_{(2,1)}=26.7, \mathrm{p}<0.001\right]$. HolmSidak post hoc analysis revealed that the squelch estimates were significantly lower for the bilateral-implant recipients than both the bimodal $(\mathrm{t}=3.4, \mathrm{p}=0.001)$ and hearing preservation $(\mathrm{t}=3.8, \mathrm{p}=0.0002)$ participants - an effect that was driven primarily by the non-CI ears for the bimodal and hearing preservation participants. There was no significant difference across the 3 subject groups for the better-hearing ear ( $\mathrm{p}>0.006$ for all comparisons). There were significant differences across the subject groups for the poorer-hearing ear with all 3 groups being significantly different from one another (bilateral vs. bimodal, $\mathrm{p}<0.0001$; bilateral vs. hearing preservation, $\mathrm{p}<$ 0.001 ; bimodal vs. hearing preservation, $\mathrm{p}=0.006$ ). 
For AzBio sentence recognition at $+5 \mathrm{~dB}$ SNR, mean squelch estimates for the bilateral CI recipients were 6.1 and 7.2 percentage points for the 1 st and 2 nd implanted ears, respectively. Mean squelch for the bimodal participants was 0.2 and 32.7 percentage points for the $\mathrm{CI}$ and HA ears, respectively. Mean squelch for the hearing preservation subjects was 1.7 and 42.1 percentage points for the CI and non-CI ears, respectively. Statistical analysis revealed a significant effect of subject group $\left[\mathrm{F}_{(2)}=5.7\right.$, $\mathrm{p}=0.004]$, a significant effect of listening condition $\left[\mathrm{F}_{(1)}=\right.$ $47.2, \mathrm{p}<0.001]$ and a significant interaction $\left[\mathrm{F}_{(2,1)}=11.9\right.$, $\mathrm{p}<0.001$ ]. Post hoc analysis using the Holm-Sidak test revealed that squelch was significantly lower for the bilateral-implant recipients than both the bimodal $(\mathrm{t}=2.8, \mathrm{p}=$ $0.0017)$ and the hearing preservation $(t=3.0, p=0.003)$ participants - as discussed above with BKB-SIN, this outcome was primarily driven by the non-CI ears for the bimodal and hearing preservation participants. There was no difference across the 3 subject groups for the betterhearing ear ( $p>0.25$ for all comparisons). There was a significant difference across the subject groups for the poorer-hearing ear with the bilateral group demonstrating significantly less squelch than both bimodal listeners $(\mathrm{p}<0.001)$ and hearing preservation $(\mathrm{p}<0.001)$ participants.

\section{Discussion}

The results of this study were largely consistent with previous reports in the literature examining availability of binaural cues for adults with bilateral implants. Mean estimates of HS for the implanted ears were consistent with previous reports in the literature ranging from 5.0 to 7.6 $\mathrm{dB}$ for the pseudoadaptive BKB-SIN (e.g. Gantz et al. [2002], Muller et al. [2002], Schon et al. [2002], Schleich et al. [2004] and Litovsky et al. [2006]) and 22.0-36.6 percentage points for AzBio sentences at $+5 \mathrm{~dB}$ (e.g. Buss et al. [2008] and Eapen et al. [2009]). Mean estimates of squelch for the bilateral-implant patients were also consistent with previous reports ranging from 0.9 to $2.3 \mathrm{~dB}$ for the BKB-SIN measure [Schleich et al., 2004; Litovsky et al., 2006] and 6.1-7.2 percentage points for AzBio sentence recognition at $+5 \mathrm{~dB}$ SNR [Buss et al., 2008; Eapen et al., 2009]. Summation was also roughly consistent with previous reports for bilaterally implanted adults, though slightly lower in this study, with mean summation being $1.0 \mathrm{~dB}$ for BKB-SIN [Schleich et al., 2004; Litovsky et al., 2006; Zeitler et al., 2008] and 8.5 percentage points for AzBio sentences at +5 dB SNR [Buss et al., 2008; Eapen et al., 2009]. Thus the results of our study with simultaneous and sequential bilateral-implant recipients replicate the findings of previous reports - most of which examined bilateral recipients who had received their implants in the same surgery.

Considering these effects for the unilateral-implant participants, estimates of HS, squelch and SRM were not significantly different from what was observed in the bilateral-implant recipients - when considering the implanted ear. Estimates of summation were also not different for the bimodal and hearing preservation subjects with acoustic hearing compared to the bilateral-implant users.

Considering the nonimplanted ear for bimodal and hearing preservation participants, estimates of squelch were significantly greater than what was observed for any of the implanted ears. The reason for this seemingly paradoxical finding is related to the underlying assumption of symmetry in performance across ears. That is to say, squelch provides information regarding improvement in speech understanding provided by adding an ear with a poorer SNR. For the bimodal and hearing preservation patients, the improvement gained by adding the implanted ear was disproportionally greater than the improvement gain for bilateral-implant users, given that the CI ear yields significantly greater speech understanding than the nonimplanted ears. So the squelch estimates for the bimodal and hearing preservation listeners simply do not provide an accurate description as the ear with the better SNR was neither the better-performing ear nor equivalent in performance to the ear with the poorer SNR. For this reason, Morera et al. [2012] suggested the use of a modified equation for describing bimodal squelch effects as follows:

squelch $=$ bimodal score (noise to non-CI ear) - CI score (noise to non-CI ear)

This is the equation we used to describe squelch for the implanted ears of bimodal and hearing preservation patients for which mean estimates were -0.7 and $0.5 \mathrm{~dB}$ for BKB-SIN and 0.2 and 1.7 percentage points for AzBio sentences at $+5 \mathrm{~dB}$.

Given that some hearing preservation patients have been shown to exhibit some preserved sensitivity to interaural time differences for low-frequency stimuli [Gifford et al., 2013], it is reasonable to ask why the hearing preservation patients in our study failed to exhibit summation and, more importantly, squelch. A number of potential explanations for this finding are likely. One may relate to the degree of summation effects that could be used in the listening paradigm used here. As seen in fig-
68

Audiol Neurotol 2014;19:57-71 DOI: $10.1159 / 000355700$ 


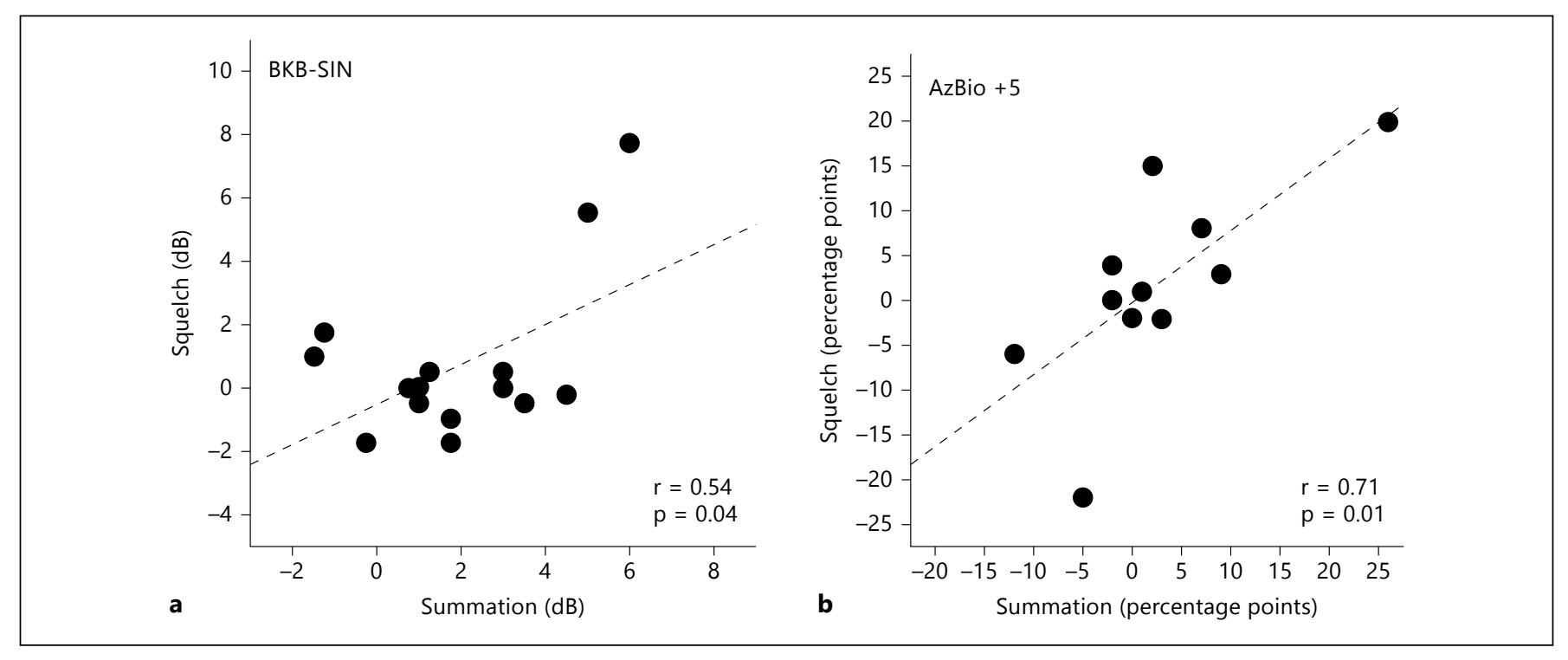

Fig. 9. Individual squelch estimates of hearing preservation patients are plotted as a function of summation for BKB-SIN (dB; a) and AzBio $+5 \mathrm{~dB}$ (percentage points; b). Diagonal dashed lines represent a linear regression function representing the Pearson correlation coefficient shown in each panel.

ure 3, the range of measurable summation for the hearing preservation patients was quite variable, with some exhibiting summation effects of $6 \mathrm{~dB}$ for BKB-SIN and 42 percentage points for AzBio at $+5 \mathrm{~dB}$. By completing correlation analyses for summation and squelch for all listener groups in our study, there was a significant positive correlation observed between summation and squelch for the hearing preservation patients $(\mathrm{BKB}-\mathrm{SIN} \mathrm{r}=0.54$, $\mathrm{p}=0.04$; AzBio $\mathrm{r}=0.71, \mathrm{p}=0.01$ ) as displayed in figure 9 . The correlation analyses for the bilateral and bimodal participants, however, were not significant for either speech metric. One could contend that these data support our hypothesis that implant recipients with preserved acoustic hearing in the implanted ear should have greater access to binaural cues. In other words, those implant recipients with bilateral acoustic hearing who exhibit summation effects in ourexperimental paradigm were also more likely to benefit from binaural squelch than both bilateral-implant recipients and bimodal listeners.

Another possible reason for the lack of binaural effects for the hearing preservation patients is the chosen test environment. Our study incorporated the classic experimental design for calculating HS and squelch including the following: $\mathrm{S}_{0} \mathrm{~N}_{0}, \mathrm{~S}_{0} \mathrm{~N}_{90}$ and $\mathrm{S}_{0} \mathrm{~N}_{270}$. Presenting noise directly to the side of the listener, as in $\mathrm{S}_{0} \mathrm{~N}_{90}$ and $\mathrm{S}_{0} \mathrm{~N}_{270}$, is not the best choice of conditions given the mic port location for CI processors and behind-the-ear (BTE) HAs.
Festen and Plomp [1986] demonstrated that the BTE mic location negatively affected SNR by $2 \mathrm{~dB}$ when speech was presented at $0^{\circ}$ compared to $\pm 90^{\circ}$. In other words, the physical SNR at the mic will be lower (i.e. poorer) with noise originating at $90^{\circ}$ or $270^{\circ}$ compared to having both speech and noise at $0^{\circ}$. As 14 of the 16 hearing preservation patients were Nucleus implant recipients, the premise of mic location affecting the outcomes in the chosen test environment may appear flawed given that directional mics have been used in cochlear processors since the introduction of the Freedom ${ }^{\mathrm{TM}}$ processor. In a description of the polar patterns of the Freedom processor, Patrick et al. [2006] showed that with speech at $0^{\circ}$ and noise at $90^{\circ}$, the signal at $90^{\circ}$ was still approximately $2-\mathrm{dB}$ higher than the signal at $0^{\circ}$ azimuth. Thus, the experimental setup had the potential to artificially inflate estimates of HS and negatively impact estimates of squelch for all subject groups in our study as well as in all previous studies for which noise was presented directly to the side of the listener. In a more diffuse-noise condition - as experienced in everyday listening environments - it may be the case that hearing preservation patients would benefit from binaural squelch.

Finally, another possible reason for the lack of binaural effects for the hearing preservation patients was the heterogeneity of electrode arrays and the range of hearing thresholds in the implanted ear. As mentioned in the Subjects section, not all of the electrodes implanted for hear- 
ing preservation were specifically designed for this purpose. Neither the Nucleus perimodiolar arrays nor the Sonata $\mathrm{H}$ (i.e. standard) electrodes were designed with hearing preservation in mind, despite having met the inclusion criteria for our study. Further investigation will continue to determine whether the purportedly atraumatic electrodes yield binaural benefit, namely summation and squelch, for implant recipients with preserved hearing.

\section{Conclusion}

We hypothesized that preserved acoustic hearing in the implanted ear - affording bilateral acoustic hearing would yield greater access to binaural cues for the hearing preservation participants. Our findings could not reject the null hypothesis. Although our study did not provide evidence for the availability of binaural cues to patients with hearing preservation, the findings may have been confounded by the test conditions. Specifically, the spatially separated noise conditions directed noise toward the mic port of the BTE HA and implant processor; this negatively affects the SNR compared to the $\mathrm{S}_{0} \mathrm{~N}_{0}$ condition [Festen and Plomp, 1986]. Given that 12 of the 16 hearing preservation listeners exhibited some binaural summation, it is possible that greater access to binaural cues may be present in more realistic listening environments.

\section{Acknowledgements}

The research reported here was supported by grant R01 DC009404 from the NIDCD to the first author. Portions of this data set were presented at the 2008 conference of the American Auditory Society in Scottsdale, Ariz., USA and the 13th Symposium on Cochlear Implants in Children (CI2011) in Chicago, Ill., USA.

\section{References}

Buss E, Pillsbury HC, Buchman CA, Pillsbury $\mathrm{CH}$, Clark MS, Haynes DS, Labadie RF, Amberg S, Roland PS, Kruger P, Novak MA, Wirth JA, Black JM, Peters R, Lake J, Wackym PA, Firszt JB, Wilson BS, Lawson DT, Schatzer R, D'Haese PS, Barco AL: Multicenter U.S. bilateral MED-EL cochlear implantation study: speech perception over the first year of use. Ear Hear 2008;29:20-32.

Dawson PW, Decker JA, Psarros CE: Optimizing dynamic range in children using the nucleus cochlear implant. Ear Hear 2004;25:230241.

Dillon H, Byrne D, Brewer S, Katsch R, Ching TY, Keidser G: NAL nonlinear version 1.01 user manual. National Acoustics Laboratories, 1998.

Dorman MF, Spahr AJ, Gifford RH, Cook S, Zhang T: Current research with cochlear implants at Arizona State University. J Am Acad Audiol 2012;23:385-395.

Dunn CC, Perreau A, Gantz BJ, Tyler RS: Benefits of localization and speech perception with multiple noise sources in listeners with a short-electrode cochlear implant. J Am Acad Audiol 2010;21:44-51.

Dunn CC, Tyler RS, Witt SA: Benefit of wearing a hearing aid on the unimplanted ear in adult users of a cochlear implant. J Speech Lang Hear Res 2005;48:668-680.

Eapen RJ, Buss E, Adunka OF, Pillsbury HC, Buchman CA: Hearing-in-noise benefit after bilateral simultaneous cochlear implantation continues to improve 4 years after implantation. Otol Neurotol 2009;30:153159.
Festen JM, Plomp R: Speech-reception threshold in noise with one and two hearing aids. J Acoust Soc Am 1986;79:465-471.

Gantz BJ, Tyler RS, Rubinstein JT: Binaural cochlear implants placed during the same operation. Otol Neurotol 2002;23:169-180.

Gifford RH, Dorman MF: The psychophysics of low-frequency acoustic hearing in electric and acoustic stimulation (EAS) and bimodal patients. J Hear Sci 2012;2:33-44.

Gifford RH, Dorman MF, Brown CA: Psychophysical properties of low-frequency hearing: Implications for perceiving speech and music via electric and acoustic stimulation. Adv Otorhinolaryngol 2010;67:51-60.

Gifford RH, Dorman MF, Skarzynski H, Lorens A, Polak M, Driscoll CLW, Roland PS, Buchman CA: Cochlear implantation with hearing preservation yields significant benefit for speech recognition in complex listening environments. Ear Hear 2013;34:413-425.

Henry P, Ricketts T: The effects of changes in head angle on auditory and visual input for omnidirectional and directional microphone hearing aids. Am J Audiol 2003;12:41-51.

Laszig R, Aschendorff A, Stecker M, Muller-Deile J, Maune S, Dillier N, Weber B, Hey M, Begall K, Lenarz T, Battmer RD, Bohm M, Steffens T, Strutz J, Linder T, Probst R, Allum J, Westhofen M, Doering W: Benefits of bilateral electrical stimulation with the nucleus cochlear implant in adults: 6-month postoperative results. Otol Neurotol 2004;25:958968.

Litovsky RY, Parkinson A, Arcaroli J, Sammeth C: Simultaneous bilateral cochlear implantation in adults: a multicenter clinical study. Ear Hear 2006;27:714-730.

Morera C, Cavalle L, Manrique M, Huarte A, Angel R, Osorio A, Garcia-Ibanex L, Estrada E, Morera-Ballester C: Contralateral hearing aid use in cochlear implanted patients: multicenter study of bimodal benefit. Acta Otolaryngol 2012;132:1084-1094.

Morera C, Manrique M, Ramos A, Garcia-Ibanex L, Cavalle L, Huarte A, Castillo C, Estrada E: Advantages of binaural hearing provided through bimodal stimulation via a cochlear implant and a conventional hearing aid: a 6-month comparative study. Acta Otolaryngol 2005;125:596-606.

Muller J, Schon F, Helms J: Speech understanding in quiet and noise in bilateral users of the MED-EL Combi 40/40+ cochlear implant system. Ear Hear 2002;23:198-206.

Patrick JF, Busby PA, Gibson PJ: The development of the Nucleus Freedom cochlear implant system. Trends Amplif 2006;10:175200

Peterson GE, Lehiste I: Revised CNC lists for auditory tests. J Speech Hear Disord 1962;27: 62-70.

Rader T, Fastl H, Baumann U: Speech perception with combined electric-acoustic stimulation and bilateral cochlear implants in a multisource noise field. Ear Hear 2013;34:324332.

Schafer EC, Amlani AM, Seibold A, Shattuck PL: A meta-analytic comparison of binaural benefits between bilateral cochlear implants and bimodal stimulation. J Am Acad Audiol 2007; 18:760-776. 
Schleich P, Nopp P, D’Haese P: Head shadow, squelch and summation effects in bilateral users of the MED-EL COMBI 40/40+ cochlear implant. Ear Hear 2004;25:197-204.

Schon F, Muller J, Helms J: Speech reception thresholds obtained in a symmetrical fourloudspeaker arrangement from bilateral users of MED-EL cochlear implants. Otol Neurotol 2002;23:710-714.

Spahr AJ, Dorman MF, Litvak LM, Van Wie S, Gifford RH, Loizou PC, Loiselle L, Oakes T, Cook S: Development and validation of the AzBio sentence lists. Ear Hear 2012;33:112-117.

Thornton AR, Raffin MJM: Speech discrimination scores modeled as a binomial variable. J Speech Hear Res 1978;21:507-518.
Tyler RS, Parkinson A, Wilson BS, Witt SA, Preece JP, Noble W: Patients utilizing a hearing aid and a cochlear implant: speech perception and localization. Ear Hear 2002;23:98-105.

Verhaert N, Lazard DS, Gnansia D, Bebear JP, Romanet P, Meyer B, Pean V, Mollard D, Truy E: Speech performance and sound localization abilities in Neurelec Digisonic ${ }^{\circledR}$ SP binaural cochlear implant users. Audiol Neurootol 2012;17:256-266.

Wackym PA, Runge-Samuelson CL, Firszt JB, Alkaf FM, Burg LS: More challenging speechperception tasks demonstrate binaural benefit in bilateral cochlear implant users. Ear Hear 2007;28:80S-85S.
Yoon YS, Li Y, Fu QJ: Speech recognition and acoustic features in combined electric and acoustic stimulation. J Speech Lang Hear Res 2012;55:105-124.

Zeitler DM, Kessler MA, Terushkin V, Roland TJJ, Svirsky MA, Lalwani AK, Waltzman SB: Speech perception benefits of sequential bilateral cochlear implantation in children and adults: a retrospective analysis. Otol Neurotol 2008;29:314-325.

Zhang T, Dorman MF, Spahr AJ: Information from the voice fundamental frequency (F0) region accounts for the majority of the benefit when acoustic stimulation is added to electric stimulation. Ear Hear 2010;31: 63-69. 